\title{
A comparative study of the literature on HIV/AIDS in Kenya and Uganda: A bibliometric study
}

\author{
Omwoyo B. Onyancha, Dennis N. Ocholla* \\ Department of Library and Information Science, University of Zululand, X1001, \\ Kwa-Dlangezwa 3886, South Africa
}

Available online 21 July 2004

\begin{abstract}
Through descriptive informetrics, HIV/AIDS research on Uganda and Kenya are compared by country, by publication type and date, by institutional affiliation, by publishing sources, by size of publications, by gender, and by nature of research collaboration. Research funding plays major role in the creation of relevant research centers in these countries and in financing research projects and research affiliates. Most publications are coauthored and focus on women, and a large proportion of HIV/AIDS documents are published outside Africa. The study recommends further research on the rest of Africa, on research collaboration, and on comparison of various population categories. The refinement of piloted research methodology and funding will be crucial for further research.
\end{abstract}

(C) 2004 Elsevier Inc. All rights reserved.

\section{Introduction}

The HIV/AID pandemic is one of the greatest catastrophes to mankind in the twentieth and twenty-first century. Shell (2000) observes that, had the HIV/AIDS pandemic been war, the human race would have long surrendered. Indeed, the epidemic has claimed a lot of lives since its discovery in the early 1980s. According to the report of the Joint United Nations Programme on HIV/AIDS_-UNAIDS (2002), forty million people were living with HIV/ AIDS as at the end of year 2001, with over 70 percent (i.e., 28.5 million) of the total number of infections occurring in sub-Saharan Africa. This forms an infection rate of 9 percent of the

\footnotetext{
* Corresponding author. Fax: +27-035-9026082.

E-mail address: docholla@pan.uzulu.ac.za (D.N. Ocholla).
} 
total population of subcontinent. The UNAIDS further estimates that sub-Saharan Africa witnessed a total of 2.2 million deaths (i.e., adults and children) in 2001 alone. This scenario has in turn led to some countries to experience negative population growth rate (International Conference on AIDS and STIs in Africa, 2003).

Kenya and Uganda are among the countries in sub-Saharan Africa that have heavily borne the load of HIV/AIDS since its diagnosis in the two countries. They have been the hardest hit by the epidemic in the Eastern African region. However, Uganda paints quite an opposite picture from that of Kenya. An assessment of the epidemiological situation indicates that, whereas Uganda has shown an improvement in curbing the spread of HIV/AIDS, Kenya's rate of HIV infections is still far from being contained. Currently, about 8 percent of Kenya's population (estimated to be 31.3 million) is living with HIV/AIDS, while Uganda reports only 600,000 (i.e., 2.5 percent of its population) cases of adults and children with HIV/AIDS as at the end of year 2001. The same year recorded 110,000 deaths associated with HIV/AIDS for Uganda, while Kenya recorded 190,000 deaths rendering an estimated number of 890,000 and 880,000 children to be orphans in Kenya and Uganda, respectively. Although the HIV/ AIDS deaths are decreasing in some areas in Kenya (Medical Letter on the CDC and FDA, 2001), the overall rate of infection still remains high. Generally, while HIV prevalence has declined in Uganda, Kenya's HIV condition is on the increase (United Nations Office for the Coordination for Humanitarian Affairs, 2003). The epidemic's negative impact in the two countries is manifested in its macroeconomic constraints on the various sectors such as social safety nets and households, health care services, education, agriculture, and infrastructure (Baltazar, Stoiver, Okeyo, Hagembe, \& Mutemi, 1999; Odiwour, 2000; Shell, 2000; UNAIDS, 1999a, 1999b).

Monitoring and evaluating research on HIV/AIDS are increasingly becoming essential and a priority to key players such as the UNAIDS and the WHO. This has, in turn, attracted several biomedical and bibliometric researchers. Both descriptive and evaluative bibliometric approaches have been used to study AIDS literature in Haiti (Macias-Chapula, 2000), Central Africa (Macias-Chapula \& Mijangos-Nolasco, 2002), Spain (Aleixandre, de la Cueva, Almero, Osca, \& Gimenez, 1995; Osca, 1997), and Latin America and the Caribbean Region (Macias-Chapula, Rodea-Castro, \& Narvez-Berthelemot, 1998; Macias-Chapula, SotolongoAguilar, Magde, \& Solorio-Lagunas, 1999). Previous studies reveal that more HIV/AIDS research is conducted on Eastern Africa than any other sub-Saharan African region (MaciasChapula \& Mijangos-Nolasco, 2002).

\section{Problem statement}

The type and nature of the documents discussed in the previous section, and the trend of collaboration and the growth of the HIV/AIDS literature in Eastern Africa, have not been explored. This in-progress study corrects that situation by examining and comparing the trends of HIV/AIDS literature on Kenya and Uganda as indexed in AIDSearch database. The study explored the following questions: What is the overall performance in HIV/AIDS research on Uganda and Kenya? What is the nature of those publications? What are the nature 
of, and trend in, collaboration? Which institutions/organizations are behind HIV/AIDS research on Uganda and Kenya? And, which is the predominant source of information on HIV/AIDS in Kenya and Uganda?

\section{Procedure}

Publications count and analysis is one of the bibliometric analytic techniques. It involves studying the number of publications in a given field, or productivity of literature in the field, with the aim of comparing "the amount of research in different countries, the amount produced during different periods, or the amount produced in different subdivisions of the field" (Hertzel, 1987, p. 156). Using that technique, the study reported here compares the HIV/AIDS research about Kenya and Uganda.

The AIDSearch database-2002 (on CD-ROM), which was used to collect the bibliographic data, is a combination of three databases: (1) the AIDSLINE (i.e., AIDS Information onLINE)-MEDLINE AIDS/HIV subset, (2) AIDSDRUGS, and (3) AIDSTRIALS. The combined database, produced by the U.S. National Library of Medicine, contains 325,000 references to information about the HIV/AIDS and related topics. AIDSLINE includes citations from journal articles, government reports, letters, technical reports, meeting abstracts/papers, monographs, special publications, theses, books, and audiovisuals. Its citations are derived from MEDLINE ${ }^{\circledR}$, CANCERLIT $^{\circledR}$, HealthSTAR, CATLINE ${ }^{\circledR}$, AVLINE ${ }^{\circledR}$, and BIOETHICSLINE files. AIDSDRUG is a dictionary of chemical and biological agents under evaluation in the AIDS clinical trials covered in the companion AIDSTRIALS database. AIDSTRIALS covers information about the clinical trials of substances being tested for use against AIDS, HIV infection, and AIDS-related opportunistic diseases.

A specific search, employing the geographic indicator (name of country, i.e., Uganda OR Kenya as subjects) was conducted using the "geographic area" field. This field features an item index consisting of the place names for the locations covered in the subjects of the database records. Unlike the key words/phrase mode of ADVANCED searching which is broad, the "Geographic Area" offers a more specific search. Hence, by limiting the search to the "Geographic Area," documents published about Kenya and Uganda, regardless of authors' country of origin, were retrieved for analysis. The aim of choosing this search strategy was to download only those documents or publications specific to the two countries.

A total of 1045 documents were retrieved, downloaded using specified fields, and analyzed. Both Bibexcel (version 2003) and Microsoft Excel-2000 softwares were used to analyze data. Specifically, Bibexcel removed duplicates and calculated the frequency distribution of the data. The file that was created was converted to Excel, which was used to sort the data according to the several variables derived from the downloaded bibliographic data.

Bibliographic data that were downloaded for analysis include the number of authors to a single paper and their names, the name of the journal, date of publication, the publication type, geographic area, source, publication country, population, the authors' addresses, and 
gender. The nature of collaboration between the authors (i.e., whether single or coauthorship) was determined by the number of author contributors, and the journal name was employed to assess the journals publishing HIV/AIDS research. The scatter of publications in journals was analyzed to determine the most prolific of these journals.

The publication date was used to examine the growth of literature and the trend of research on both countries. In order to compare different types of documents with the view to determining the most used channel of communication of HIV/AIDS research, the publication type was employed, while the geographic area (i.e., name of country) helped in the analysis of data according to country. The "source" field assisted in evaluating the sizes of the documents.

The publication country helped in the analysis of data according to the country where the publications were published, while the "population" field was used to download and analyze only the documents that concern human beings. Only documents whose "population" check tag was "human" or "human; animal" were included in this study. Excluded in this study were records, which concerned animals only.

Finally, the authors' addresses assisted in comparing research by institutional affiliation and thus helped to determine the institutions most responsible for HIV/AIDS research on Uganda and Kenya. Data were also analyzed by "sex" in order to determine which group (i.e., male or female) that was given greater attention by researchers.

\section{Findings}

Of the 1045 documents, 369 (35.3 percent) were on HIV/AIDS in Kenya and 676 (64.7 percent) were on Uganda. Seven ( 0.7 percent) documents were shared by the two countries. In other words, research featuring the HIV/AIDS pandemic in Uganda and Kenya was jointly reported in seven publications.

\subsection{HIV/AIDS research on Uganda and Kenya: comparison by publication type}

An analysis of data according to the publication type indicates that there were four types of publications, namely, meeting abstracts, journal articles, monographs, and newspaper articles. Meeting abstracts consisted of 344 records on Kenya and 650 on Uganda making a total of 994 (95.1 percent), while journal articles comprised of sixteen on Kenya and eleven on Uganda. The total number of journal articles was twenty-seven (2.6 percent). Table 1 shows that monographs totaled 22 (2.1 percent) with Kenya's and Uganda's shares being nine and thirteen, respectively. The only two newspaper articles retrieved were on Uganda.

\subsection{HIV/AIDS research on Uganda and Kenya: comparison by publication year}

Fig. 1, which compares research output in Kenya and Uganda, indicates the trend of publishing of HIV/AIDS research on the two countries by the year of publication. Throughout the period of 1989-2000, Kenya's publications remained well below those on Uganda. 
Table 1

HIV/AIDS research: comparison by publication type $(N=369$ for Kenya, 676 for Uganda, and 1045 for both countries)

\begin{tabular}{|c|c|c|c|c|c|c|}
\hline \multirow{2}{*}{ Publication type } & \multicolumn{2}{|c|}{$\underline{\text { HIV/AIDS research on Kenya }}$} & \multicolumn{2}{|c|}{ HIV/AIDS research on Uganda } & \multicolumn{2}{|l|}{ Total } \\
\hline & No. & $\%$ & No. & $\%$ & No. & $\%$ \\
\hline Meeting abstracts & 344 & 93.2 & 650 & 96.2 & 994 & 95.1 \\
\hline Journal articles & 16 & 4.4 & 11 & 1.6 & 27 & 2.6 \\
\hline Monographs & 9 & 2.4 & 13 & 1.9 & 22 & 2.1 \\
\hline Newspaper articles & - & & 2 & 0.3 & 2 & 0.2 \\
\hline Total & 369 & 100 & 676 & 100 & 1045 & 100 \\
\hline
\end{tabular}

However, the two countries witnessed similar patterns of research output. Except for the 1990/1991 period where there was a difference in growth of publications (i.e., an increase for Kenya and a decrease for Uganda), the pattern is similar.

In both countries, there was a downward trend between 1989 and 1990 from a total of fifty-eight publications to forty-one and a slight increase to forty-three publications in 1991. This was followed by a sharp rise by a growth rate of approximately 190 percent to 125 publications in 1992. Within the same period, Kenya's publications grew by twenty-nine publications (an increase of 181.3 percent) while Uganda's production increased by 196.3 percent to eighty publications. Thereafter, production remained almost the same throughout the 1993/1994 period for both countries. The Figure further illustrates that there was a low research output in 1995, 1997, 1999, and 2000 where the total number of publications did not exceed fifteen in each year. However, 1996 and 1998 recorded 212 and 291 records, respectively. Both countries witnessed the largest production in these two periods. The least number of publications was witnessed in year 2000 where one publication was on Kenya and

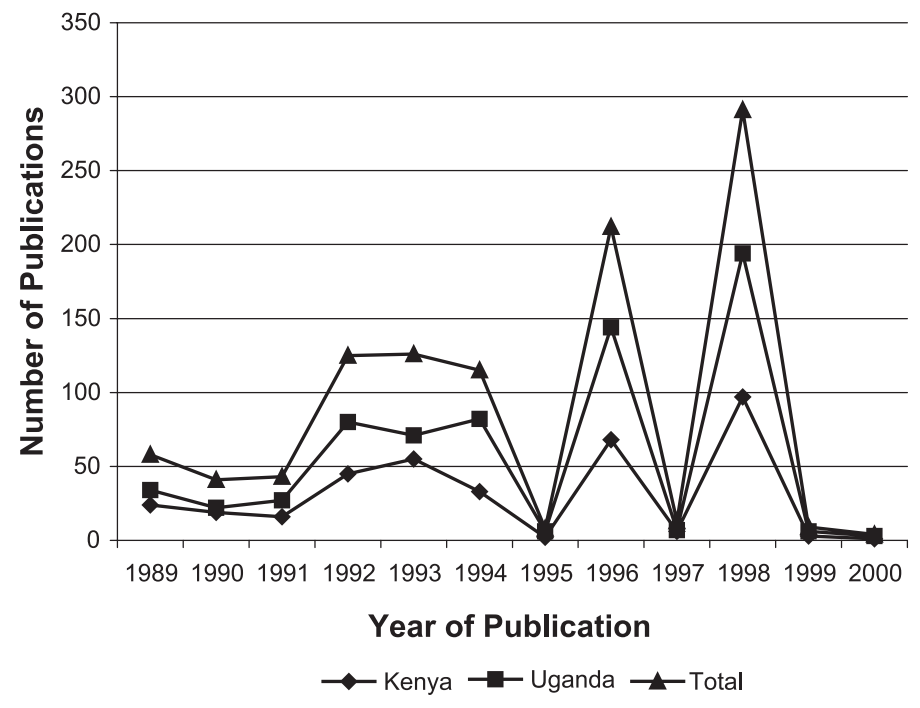

Fig. 1. HIV/AIDS research: comparison by year of publication. 
three on Uganda, totaling only four documents. It can also be seen that no documents were published earlier than 1989.

\subsection{HIV/AIDS research on Uganda and Kenya: comparison by institutional affiliation}

Table 2 compares the top ten institutions that contributed to the publication of HIV/AIDS literature on Uganda and Kenya. Some 215 institutions were responsible for the production of $676 \mathrm{HIV} /$ AIDS publications on Uganda between 1989 and 2000 with the majority (seventyone; 10.5 percent) coming from Makerere University. The university's Institute of Public Health produced five documents while the Department of Social Work and Social Administration contributed three. The Medical School and the Departments of Pediatrics and Psychology produced two publications each, while the Departments of History, Pathology, Obstetrics \& Gynecology, and Literature, among others, produced one document each. Other institutions that contributed to the publication of HIV/AIDS literature on Uganda include The AIDS Support Organization-TASO (forty; 5.9 percent), the Medical Research Institute (thirty-six; 5.3 percent), and Ministry of Health-MOH (thirty-three; 4.9 percent), among others.

On its part, Kenya's HIV/AIDS research was more concentrated at the University of Nairobi. Overall, 108 institutions contributed to the total number of publications on HIV/ AIDS in Kenya. The University of Nairobi produced ninety-nine publications with the Department of Medical Microbiology producing the largest number of publications (fourteen). The university was followed by the Kenya Medical Research Institute (KEMRI) with thirty-two (8.9 percent) publications, the Association of People with AIDS in Kenya-

Table 2

HIV/AIDS research: comparison by institution/organization ( $N=369$ for Kenya and 676 for Uganda)

\begin{tabular}{|c|c|c|c|c|c|c|}
\hline & \multicolumn{3}{|l|}{ HIV/AIDS research in Kenya } & \multicolumn{3}{|l|}{ HIV/AIDS research in Uganda } \\
\hline & Institution/organization & No. & $\%$ & Institution/organization & No. & $\%$ \\
\hline 1 & University of Nairobi, Kenya & 99 & 26 & Makerere University, Uganda & 72 & 10.7 \\
\hline 2 & KEMRI, Kenya & 32 & 8.9 & $\begin{array}{l}\text { The AIDS Support Organization } \\
\text { (TASO), Uganda }\end{array}$ & 40 & 5.9 \\
\hline 3 & TAPWAK, Kenya & 16 & 4.3 & Medical Research Council, Uganda & 36 & 5.3 \\
\hline 4 & $\begin{array}{l}\text { University of Washington, } \\
\text { Seattle, USA }\end{array}$ & 13 & 3.5 & Ministry of Health $(\mathrm{MOH})$, Uganda & 33 & 4.9 \\
\hline 5 & University of Manitoba, Canada & 10 & 2.7 & Joint Clinical Research Center, Uganda & 17 & 2.5 \\
\hline 6 & AIDSCAP, Arlington, USA & 9 & 2.4 & University of Cleveland, USA & 17 & 2.5 \\
\hline 7 & $\begin{array}{l}\text { Centers for Disease Control and } \\
\text { Prevention, Atlanta, GA, USA }\end{array}$ & 7 & 1.9 & AIDS Information Centre, Uganda & 14 & 2.1 \\
\hline 8 & Kenya AIDS Society, Kenya & 7 & 1.9 & $\begin{array}{l}\text { Uganda Virus Research Institute } \\
\text { (UVRI), Uganda }\end{array}$ & 13 & 1.9 \\
\hline 9 & WOFAK, Kenya & 6 & 1.6 & Uganda AIDS Commission, Uganda & 12 & 1.8 \\
\hline 10 & $\begin{array}{l}\text { Kenya National AIDS } \\
\text { and STDS, Kenya }\end{array}$ & 5 & 1.4 & CONCERN & 12 & 1.8 \\
\hline
\end{tabular}


TAPWAK (sixteen; 4.3 percent), University of Washington, Seattle (thirteen; 3.5 percent), and the University of Manitoba (ten; 2.7 percent).

\subsection{HIV/AIDS research on Uganda and Kenya: comparison by publication country}

Only 99.6 percent of the publications provided information on the publication country. As Table 3 indicates, HIV/AIDS publications on Uganda were published in fifteen countries, whereas those on Kenya were produced in ten countries. The majority of the publications on both countries were published in Switzerland, which tops both lists with 185 and ninety-one publications on Uganda and Kenya, respectively. In total, Switzerland produced 276 (26.5 percent) of the publications. In the second position is Canada with 157 publications on Uganda and eighty-seven on Kenya. Other countries in which over ten publications were published include Japan, Netherlands, Germany, United States, Italy, Kenya, and England. The rest of the countries reported less than ten publications. It can also be noted that the countries where research on HIV/AIDS in Kenya has not been published but authors have used to publish their findings on HIV/AIDS in Uganda include Australia, Denmark, France, Scotland, and Uganda. Finally, authors published the least number of publications (i.e., one) in Denmark and Kenya on Uganda and South Africa in the case of Kenya.

\subsection{HIV/AIDS research on Uganda and Kenya: comparison by publishing sources}

Table 4 shows the sources publishing HIV/AIDS literature on Kenya and Uganda. There are a total number of thirty-five publication sources. The table illustrates that the Int Conf

Table 3

HIV/AIDS research: comparison by publication country $(N=1041)$

\begin{tabular}{|c|c|c|c|c|c|}
\hline \multirow{2}{*}{ No. } & \multirow{2}{*}{ Publication country } & \multicolumn{2}{|l|}{ Country } & \multicolumn{2}{|l|}{ Total } \\
\hline & & Uganda & Kenya & No. & $\%$ \\
\hline 1 & Switzerland & 185 & 91 & 276 & 26.5 \\
\hline 2 & Canada & 157 & 87 & 244 & 23.4 \\
\hline 3 & Japan & 80 & 31 & 111 & 10.7 \\
\hline 4 & Netherlands & 79 & 43 & 122 & 11.7 \\
\hline 5 & Germany & 70 & 51 & 121 & 11.6 \\
\hline 6 & United States & 53 & 34 & 87 & 8.4 \\
\hline 7 & Italy & 25 & 14 & 39 & 3.6 \\
\hline 8 & Kenya & 1 & 11 & 12 & 1.2 \\
\hline 9 & England & 6 & 5 & 11 & 1.1 \\
\hline 10 & Uganda & 7 & - & 7 & 0.7 \\
\hline 11 & Australia & 4 & - & 4 & 0.4 \\
\hline 12 & France & 2 & - & 2 & 0.2 \\
\hline 13 & Scotland & 2 & - & 2 & 0.2 \\
\hline 14 & South Africa & 1 & 1 & 2 & 0.2 \\
\hline \multirow[t]{2}{*}{15} & Denmark & 1 & - & 1 & 0.1 \\
\hline & Total & 673 & 368 & 1041 & 100 \\
\hline
\end{tabular}


Table 4

HIV/AIDS research: distribution of publications by publishing source $(N=1015)$

\begin{tabular}{|c|c|c|c|c|}
\hline \multirow{2}{*}{ Name of source } & \multicolumn{2}{|c|}{ No. of publications } & \multicolumn{2}{|l|}{ Total } \\
\hline & Uganda & Kenya & No. & $\%$ \\
\hline Int Conf AIDS & 327 & 187 & 514 & 50.6 \\
\hline America & 197 & 92 & 289 & 28.4 \\
\hline $\begin{array}{l}\text { Kroniek van het Ambacht, } \\
\text { Klein-en Miden bedrijf }\end{array}$ & 104 & 57 & 161 & 15.8 \\
\hline Conf Adv AIDS Vaccine Dev & 3 & 2 & 5 & 0.5 \\
\hline Natl Conf Women HIV & 2 & 2 & 4 & 0.4 \\
\hline Annu Conf Australas Soc HIV Med & 4 & - & 4 & 0.4 \\
\hline East African Medical Journal & 1 & 3 & 4 & 0.4 \\
\hline Conf Retroviruses Opportunistic Infect & 3 & & 3 & 0.3 \\
\hline Sexually Transmitted Infections & 1 & 2 & 3 & 0.2 \\
\hline $\begin{array}{l}\text { American Society for Microbiology. } \\
\text { Abstracts of the General Meeting }\end{array}$ & 2 & - & 2 & 0.2 \\
\hline Abstr Book Assoc Health Serv Res & - & 1 & 1 & 0.1 \\
\hline Clinical Infectious Diseases & - & 1 & 1 & 0.1 \\
\hline $\begin{array}{l}\text { American Journal of Respiratory and } \\
\text { Critical Care Medicine }\end{array}$ & 1 & - & 1 & 0.1 \\
\hline Annals of Tropical Medicine and Parasitology & - & 1 & 1 & 0.1 \\
\hline British Journal of Cancer & 1 & & 1 & 0.1 \\
\hline European Journal of Immunology & - & 1 & 1 & 0.1 \\
\hline European Respiratory Journal & 1 & & 1 & 0.1 \\
\hline Health Policy and Planning & 1 & - & 1 & 0.1 \\
\hline Infection Control and Hospital Epidemiology & - & 1 & 1 & 0.1 \\
\hline $\begin{array}{l}\text { International Journal of Tuberculosis } \\
\text { and Lung Disease }\end{array}$ & 1 & - & 1 & 0.1 \\
\hline $\begin{array}{l}\text { Interscience Conference on Antimicrobial Agents } \\
\text { and Chemotherapy. Program and Abstracts }\end{array}$ & 1 & - & 1 & 0.1 \\
\hline Journal of Antimicrobial Chemotherapy & - & 1 & 1 & 0.1 \\
\hline Journal of Immunology & - & 1 & 1 & 0.1 \\
\hline Journal of Infectious Diseases & - & 1 & 1 & 0.1 \\
\hline New York Times & 1 & - & 1 & 0.1 \\
\hline $\begin{array}{l}\text { Pediatric AIDS and HIV Infection: } \\
\text { Fetus to Adolescent }\end{array}$ & 1 & - & 1 & 0.1 \\
\hline Preventive Veterinary Medicine & 1 & - & 1 & 0.1 \\
\hline Sexually Transmitted Diseases & - & 1 & 1 & 0.1 \\
\hline Social Science and Medicine & 1 & - & 1 & 0.1 \\
\hline Symp Nonhum Primate Models AIS & - & 1 & 1 & 0.1 \\
\hline Tropical Doctor & 1 & - & 1 & 0.1 \\
\hline Tubercle and Lung Disease & 1 & - & 1 & 0.1 \\
\hline $\begin{array}{l}\text { U.S. Centers for Disease Control and } \\
\text { Mortality Weekly Report }\end{array}$ & - & 1 & 1 & 0.1 \\
\hline Washington Post & 1 & - & 1 & 0.1 \\
\hline World Health Organization. Bulletin & - & 1 & 1 & 0.1 \\
\hline Total & 657 & 358 & 1015 & 100 \\
\hline
\end{tabular}


AIDS is the most used "source" in publishing HIV/AIDS literature on the two countries. This source published half of the publications (i.e., 514; 50.6 percent). It consisted of 327 publications on Uganda and 187 on Kenya. In the second and third positions are the America and the Kroniek van het Ambacht, which published 289 and 161, respectively. The rest published no more than five documents.

\subsection{HIV/AIDS research on Uganda and Kenya: comparison by the publication size}

The size of each retrieved document was calculated using the "source" field. Majority of the documents (1020; 97.6 percent) were between one and four pages long (see Table 5). Of these, 354 were on Kenya while those on Uganda totaled 666 publications. Documents that were between five and nine pages long totaled eighteen (1.7 percent), which therefore indicates that 1038 (99.3 percent) documents were less than ten pages long. According to Table 5, only one document exceeded thirty pages but two had fifty-three and ninety-two leaves in that order.

\subsection{HIV/AIDS research on Uganda and Kenya: comparison by gender}

The majority of HIV/AIDS publications in the two countries (206; 38.1 percent) were on females only while those on the males only were thirty-eight ( 7.0 percent). Of the 212 publications on Kenya, twenty-two (10.4 percent) were on males only, ninety-one (42.9 percent) considered both sexes, while ninety-nine (46.7 percent) were specifically on women. The distribution of the literature on Uganda by gender revealed that of the total 328 publications, sixteen (4.9 percent) focused on males, 205 (62.5 percent) discussed AIDS as it affects both sexes, and 107 (32.6 percent) were specifically on women. However, 190 publications focused on females in Kenya while those on males were 113 publications. In the case of Uganda, a total of 221 and 312 publications, respectively, dealt with males and females.

Table 5

HIV/AIDS research: comparison by the publication size $(N=1045)$

\begin{tabular}{lrrrr}
\hline $\begin{array}{l}\text { Size of publications } \\
\text { in pages }\end{array}$ & Kenya & Uganda & Total & Percentage \\
\hline $1-4$ & 354 & 666 & 1020 & 97.6 \\
$5-9$ & 12 & 6 & 18 & 1.7 \\
$10-14$ & 1 & 1 & 2 & 0.2 \\
$15-19$ & 1 & 0 & 1 & 0.1 \\
$20-24$ & 0 & 0 & 0 & 0.0 \\
$25-29$ & 0 & 1 & 0 & 0.0 \\
$30-34$ & 0 & 1 & 1 & 0.1 \\
53 leaves & 0 & 1 & 2 & 0.1 \\
92 leaves & 1 & 676 & 1045 & 0.1 \\
Total & 369 & & & 100 \\
\hline
\end{tabular}




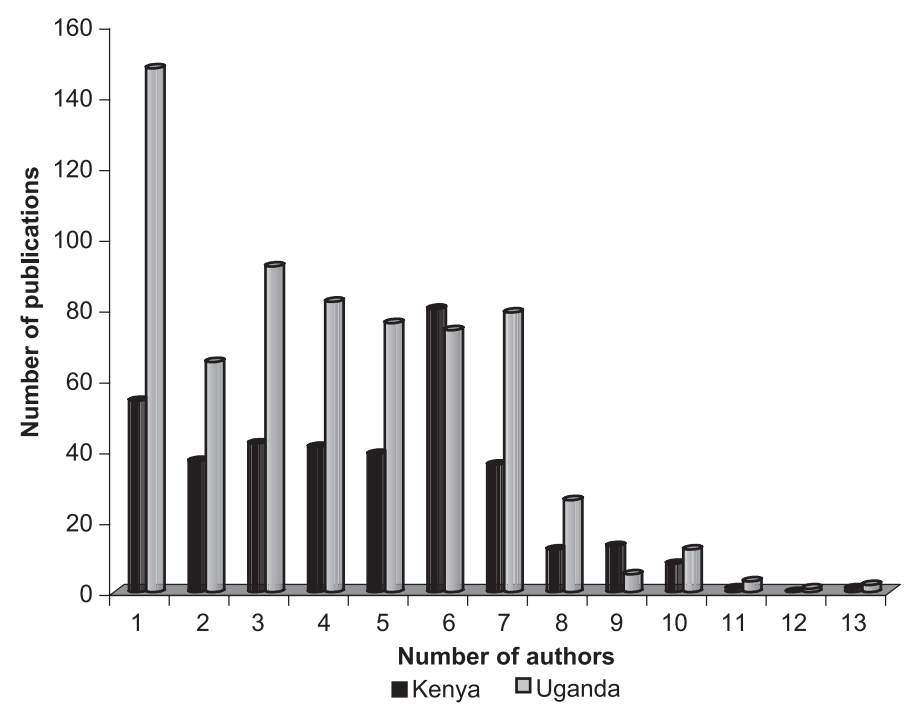

Fig. 2. HIV/AIDS research: comparison by the nature of author collaboration.

4.8. HIV/AIDS research on Uganda and Kenya: comparison by nature of author collaboration

Fig. 2, which illustrates the nature of coauthorship or collaboration, provides the number of publications that were each authored by $x$ number of authors. Of the 1029 records that provided the authors' names, 80.4 percent were each jointly authored by two or more authors while only 19.6 percent were each single authored. Kenya's single-authored publication was fifty-four (14.8 percent) and Uganda's equivalent totaled 148 (22.3 percent). This means that two or more authors wrote 85.2 percent of Kenya's and 77.7 percent of Uganda's total publications. Fig. 2 also shows that thirteen-author papers were only three ( 0.3 percent). Therefore, the largest number of authors to have coauthored an article on HIV/AIDS in Kenya and Uganda are thirteen.

\section{Discussion}

The total number of publications produced on the two countries (i.e., 1045) represents 31.9 percent of the Eastern African total publications, which adds up to 3275 (10.2 percent) of the entire sub-Saharan Africa, according to a previous study conducted by Macias-Chapula and Mijangos-Nolasco (2002). Kenya produced fewer publications than Uganda during the entire period, a situation that can be attributed to many varied factors. Some of which may have contributed to the discrepancy and which may require further investigation could be the number of research centers. For instance, Cohen (2000) observes that there were four key AIDS research centers in Uganda, namely, Makerere University, Mulago Hospital, Uganda 
Virus Research Institute, and Lacor Hospital, whereas Kenya's collaborative research centers were the University of Nairobi and the Ministry of Health. These institutions contributed a substantive number of publications in the two countries. The assumption here is that the research centers seem to bear the bulk of HIV/AIDS-related research and publications in a given country. Similarly, research-funding agencies increasingly finance research centers whose research output is considerably larger than those originating from other research generating agencies. Arguably, research centers in the region are staffed with a significant number of expatriates who facilitate the research process since such staff have to account for their research to the sponsors largely through publication. In this respect, Cohen (2000) indicates that in 1980 Kenya received its external HIV/AIDS funds, which amounted to US\$3.6 million, from Canada’s Medical Research Council, National Institutes of Health (US), the Medical Research Council (UK), International AIDS Vaccine Initiative (IAVI), and the U.S. Agency for International Development. Uganda's external sources of HIV/AIDS funding between 1986 and 1998, which totaled US\$24.7 million, came from NIH and the U.K. Medical Research Council. These figures indicate that the ratio of Kenya's external funding compared to that of Uganda is approximately 1:7. If the observation that "output indicators can be used to derive robust input indicators for research in a given subject area" (Lewison, Lipworth, \& de Francisco, 2002) holds true, then it follows that the small number of publications that were published about HIV/AIDS in Kenya reflects the little funding that was channeled by the external donors. Uganda's large amount of literature, on the other hand, accrues from substantial amount of money dedicated to HIV/AIDS research in the region. The Uganda government's honorable fight against HIV/AIDS is well documented.

As regards the nature of authorship, there were more coauthored publications than there were single authored. Similar findings were observed by Macias-Chapula and MijangosNolasco (2002) in their study on Central Africa. Unlike humanities and social sciences, where coauthorship is thought to be minimal (Onyancha \& Ocholla, 2002), it seems that most biomedical research activities are conducted between two or more authors (Ravi, 2001; Garg, 2001; Cunningham, 2001 in Onyancha and Ocholla, 2002). These authors note that today's research and development activities are collective and not individualistic in nature.

Countries that were jointly analyzed alongside with Kenya and Uganda demonstrated the relevance external funding and collaborative efforts in HIV/AIDS research. This study, however, could not ascertain the extent of foreign collaboration by institution or country due to the lack of data. The AIDSearch database provides only the addresses of the first named author. The coauthors' addresses are not provided, making it difficult to know the countries and/or institutions collaborating with Kenya and Uganda in HIV/AIDS research. However, according to Cohen (2000), Uganda's main collaborating institutions include Johns Hopkins University, Case Western Reserve University, Imperial College (London), Institute of Tropical Medicine (Antwerp), U.K. Medical Research Council, the U.S. NIAID, and the University of Milan. Kenya's collaborators are the University of Manitoba, University of Washington, University of Ghent, Oxford University, and the Institute of Tropical Medicine. Majority of these institutions greatly featured in this study as some of the most prolific (see Table 2). Their collaborative activities are centered on the research centers/institutions named above. 
An analysis of data by gender revealed that the HIV/AIDS literature focusing on women (38.1 percent) was higher than those focusing on men (7.0 percent). According to the World Health Organization (WHO) (2002), women are said to be biologically, economically, socially, and culturally vulnerable and thus at high risk of infection from HIV/AIDS. The ratio of infection in Africa is twelve to thirteen African women for every ten African men. The WHO further observes that 55 percent of adult infections in sub-Saharan Africa are women and that half a million children get infected by their HIV positive mothers. In Kenya alone, while 900,000 men were HIV positive as at 2001, there were 1.4 million women with the HIV infection. Uganda's ratio was 230,000 men to 280,000 women. This scenario may well explain why there was more research on HIV/AIDS targeting women when compared to men. Furthermore, major nongovernmental organizations and other key players in the fight against HIV/AIDS such as the WHO and UNAIDS advocate for a gender-based response to the prevention of the spread of AIDS. This may, in turn, have a bias in funding HIV/AIDS research projects that are related to women and hence more publications.

Although previous studies describe the growth of AIDS literature as exponential (Sengupta \& Kumari, 1991; Wyatt, 1988; Pratt, 1992 in Macias-Chapula et al., 1998), the present study did not find any particular and definite pattern in the literature growth. Seemingly, a larger target population may yield a better and clear picture regarding the growth of AIDS literature. Nevertheless, it is possible to predict the publishing trends of the HIV/AIDS literature. As discussed in Section 4.2, any increase is immediately followed by a decrease in the number of publications, except for the 1999/2000 period. This trend may therefore be used to forecast future trends of HIV/AIDS research on Kenya and Uganda and assist in making policy decisions on strategizing HIV/AIDS research. Whereas the disease was diagnosed in 1982 in Uganda and 1984 in Kenya, the first published document appeared in 1989. This implies that the average publishing time lag is five to seven years.

Except for Kenya, Uganda and South Africa, which published a total of twenty-one publications, all countries behind the publication of the rest of the HIV/AIDS literature were from outside Africa, which most probably shows that local authors prefer to publish their research findings in foreign sources. Table 4 supports this view since the majority of the sources of HIV/AIDS publications are foreign based. Besides, since most research funds originate from outside Africa, it seems likely that donors greatly influence where the research findings are published.

Meeting abstracts, which Macias-Chapula and Mijangos-Nolasco (2002, p. 315) found to have "important implications for information scientists and librarians," and covered 95.1 percent of the publications, are indicative of the nature of the sources of the publications. In essence, they show that the majority of the HIV/AIDS documents on Uganda and Kenya originated from meetings (i.e., conferences, proceedings, workshops, or seminars). Whether indicative or informative, extract or critical, abstracts are meaningful research resources besides being "highly valued as a condensed and comprehensible representation of a text's content" (Moens, 2000, p. 54). No doubt they are important. Journal and newspaper articles, on the other hand, seem to be a rarely used means of communicating HIV/AIDS research. Monographs were highly regarded in publishing HIV/AIDS research on Kenya and Uganda. 


\section{Conclusion}

In conclusion, although Uganda has, for a long time, been unstable politically from the persistent fights - a situation that could have hindered effective research-research activities regarding HIV/AIDS were focused on the country more than Kenya. One would have expected more HIV/AIDS research on Kenya, throughout the entire period of study, considering Kenya's continued increase in HIV infections besides the country's favorable research environment. The government of Kenya and other stakeholders involved in the formulation of policies on research in HIV/AIDS should vigorously campaign for more research funds and other resources that have made Uganda's case a success. Collaborative links with foreign researchers should also be strengthened.

This comparative study on HIV/AIDS research on Kenya and Uganda demonstrates the use of descriptive bibliometric techniques in assessing the research outputs on a given geographical region. Further research is however recommended to investigate the scientific impact of HIV/AIDS in Kenya and Uganda. We further recommend that other key bibliographic databases be used to analyze, for instance, the type of collaboration in HIV/AIDS research given the inadequacy of the MEDLINE database to provide the coauthors' addresses. This being a preliminary study on HIV/AIDS research in sub-Saharan Africa, it is hoped that several bibliometric indicators would ultimately be identified for purposes of evaluating HIV/AIDS research in the region.

\section{References}

Aleixandre, R., de la Cueva, A., Almero, A., Osca, J., \& Gimenez, J. V. (1995). 10 years of literature on AIDS (1983-1992): Bibliometric analysis. Enfermedades Infecciosas y Microbiologia Clinica, 13, 338-344.

Baltazar, G. M., Stoiver, J., Okeyo, T. M., Hagembe, B., \& Mutemi, R. (Eds.). (1999). AIDS in Kenya: Background, projections, impact and interventions. Nairobi, Kenya: Ministry of Health, National AIDS and STD Control Programme.

Cohen, J. (2000). Balancing the collaboration equation. Science, 288, 2155-2159.

Hertzel, D. (1987). Bibliometrics, history of the development of ideas: Statistical bibliography or bibliometrics? In A. Kent, \& H. Lancour (Eds.), Encyclopedia of Library and Information Science, vol. 42 (pp. 144-219). New York: M. Dekker.

International Conference on AIDS and STIs in Africa. (2003). Challenges: Conference background. (Available: http://icasanairobi2003.org/icasa_bg.htm. Accessed April 17, 2003).

Lewison, G., Lipworth, S., \& de Francisco, A. (2002). A bibliometric approach to estimating malaria research funding. (Available: http://www.globalforumhealth.org/forum_6/sessions/3thursday/4ResourcesLewisonFull. doc. Accessed January 25, 2003).

Macias-Chapula, C. A. (2000). AIDS in Haiti: A bibliometric analysis. Bulletin of the Medical Library Association, 88, 56-60.

Macias-Chapula, C. A., \& Mijangos-Nolasco, A. (2002). Bibliometric analysis of AIDS literature in Central Africa. Scientometrics, 54, 309-317.

Macias-Chapula, C. A., Rodeo-Castro, I. P., \& Narvez-Berthelemot, N. (1998). Bibliometric analysis of AIDS literature in Latin America and the Caribbean. Scientometrics, 41(1-2), 41-49.

Macias-Chapula, C. A., Sotolongo-Aguilar, G. R., \& Magde, B. (1999). Subject content analysis of AIDS literature, as produced in Latin America and the Caribbean. Scientometrics, 46, 563-574.

Medical Letter on the CDC \& FDA. (2001). HIV/AIDS deaths are decreasing in some areas of Kenya. Medical 
Letter on the CDC \& FDA (2001):12. Available from: EBSCO Academic Search Premier Database. Accessed April 23, 2003.

Moens, M. (2000). Automatic indexing and abstracting of document texts. Boston, MA: Kluwer.

Odiwour, W. H. (2000). HIV/AIDS and primary education in Kenya. Stockholm, Sweden: Institute of International Education, Stockholm University.

Onyancha, O. B., \& Ocholla, D. N. (2002). An informetric analysis of the corruption literature based on Africa between 1990 and 2001. In T. J. D. Bothma, \& A. Kaniki (Eds.), Proceeding of the 2nd biennial ProLISSA Conference, Pretoria, 24-25 October (pp. 105-124). Pretoria, South Africa: Infuse, Available: http:// www.dissanet.com/.

Osca, J. (1997). Spanish bibliographic production on AIDS. Bibliometric approach. Enfermedades Infecciosas y Microbiologia Clinica, 15(8), 407-410 (Available: AIDSearch CD-ROM, 2002. Accessed February 14, 2003).

Shell, R. (2000, July). AIDS: We must go to war. Reader's Digest, 49-55.

The Joint United Nations Programme on HIV/AIDS. (1999a). The demographic impact of HIV/AIDS. Available from: Medical and Health Library CD-ROM, December 2000. Accessed February 14, 2003.

The Joint United Nations Programme on HIV/AIDS. (1999b). Intensifying action against HIV/AIDS in Africa: Responding to a development crisis. Available from: Medical and Health Library CD-ROM, December 2000. Accessed February 14, 2003.

The Joint United Nations Programme on HIV/AIDS. (2002). Report on the global HIV/AIDS epidemic, 2002. Available: http://www.unaids.org/en/default.asp. Accessed February 3, 2003.

United Nations Office for the Coordination for Humanitarian Affairs. (2003). PlusNews country briefs. Available: http://www.irinnews.org/aids/profiles.asp. Accessed May 22, 2003.

World Health Organization. (2002). Women and HIV/AIDS. Available: http://www.who.int/inf-fs/en/fact242.html. Accessed May 22, 2003. 